\title{
Weight Loss and Eating Behavior following Vertical Banded Gastroplasty
}

\author{
Gerbrand C.M. van Hout, MSc'; Jack J. Jakimowicz, MD²; Frederiek A.M. \\ Fortuin, MSc ${ }^{1}$; Aline J.M. Pelle, MSc ${ }^{3}$; Guus L. van Heck, PhD ${ }^{3}$
}

\begin{abstract}
${ }^{1}$ Department of Medical Psychology, ${ }^{2}$ Department of Surgery, Catharina Hospital, Eindhoven, the Netherlands; ${ }^{3}$ Department of Psychology and Health, Medical Psychology, Tilburg University, the Netherlands
\end{abstract}

Background: Bariatric surgery is the treatment of choice for patients with morbid obesity. In addition to surgery, postoperative dietary behavior is an important mediator of weight loss and, therefore, critical in influencing outcome. Surgical treatment of obesity is not an alternative to dieting but a method to enforce dieting.

Methods: We evaluated early weight loss and postoperative eating behavior over time. Preoperatively as well as 6 months, 1 and 2 years after vertical banded gastroplasty (VBG), 91 patients were psychologically assessed using a semi-structured interview and a psychological questionnaire focusing on eating behavior.

Results: Over time, we found significant changes in weight, mostly in the 1st postoperative year (EWL= $52.0 \%$ ); at 2 years, EWL was $61.5 \%$. Patients reported substantial changes in feelings of hunger, appetite, satiety, and eating behavior; however, most improvements waned over time. In addition, there was a wide variability in changes within our patient group, and changes in weight loss appeared to be related to changes in restrained eating.

Conclusion: VBG not only leads to considerable weight loss, but also to significant improvements in eating behavior, at least within 2 years. However, most improvements wane over time and not all patients profit in the same way.

Key words: Morbid obesity, bariatric surgery, vertical gastroplasty, psychology, eating behavior

Correspondence to: Gerbrand van Hout, Catharina Hospital, Department of Medical Psychology, P.O. Box 1350, 5602 ZA Eindhoven, the Netherlands. E-mail: gerbrand.v.hout@cze.nl

\section{Introduction}

According to the World Health Organization, obesity is one of the largest public health concerns; the prevalence of obesity is increasing globally, in developed as well as in developing countries. ${ }^{2}$ Worldwide, there are more than one billion people overweight, 300 million of them being obese. ${ }^{3}$ Morbid obesity is associated with an increased risk of morbidity and mortality from numerous related medical conditions. ${ }^{4}$ Morbid obesity is also associated with debilitating psychological and social consequences, and poor quality of life, especially in patients seeking surgery for their condition. ${ }^{5}$

Surgical treatment is the only intervention resulting in long-term weight reduction; ${ }^{6}$ as a consequence, the number of operations performed has more than doubled within a few years. ${ }^{7}$ Bariatric surgery not only leads to substantial weight reduction, but also to improvement or cure of co-morbidities, including diminishing of psychopathology and abnormal eating behavior. ${ }^{5}$ However, studies show great variation in outcome, some studies suggesting that postoperative improvements may lag behind the psychosocial functioning of norm groups, showing no significant changes, or even worsening of psychosocial functioning. ${ }^{6}$ Also, some years after bariatric surgery, weight may stabilize or even increase, and related improvements may diminish. ${ }^{89}$

In addition to medical-somatic and surgical-technical factors, success of batriatric surgery is influenced by the extent of successful adjustment of eat- 
ing behavior, following adequate dietary rules. On the one hand, surgical treatment is a method to enforce dieting, but on the other hand, this compliance and adjustment can be attributed to psychological factors, implying that the operation on its own represents only one element in bariatric surgery. ${ }^{10}$ Therefore, success following bariatric surgery should not only include weight loss and improvement or cure of co-morbid conditions, but also improvement in eating behavior, psychosocial variables, and quality of life. " Unfortunately, in contrast to physical changes, psychosocial changes have not yet been studied as systematically or diligently, and therefore remain to be fully understood. ${ }^{8}$

\section{Materials and Methods}

The present study was designed to understand patients' changes in eating behavior during the first 2 years following vertical banded gastroplasty (VBG): what specific improvements can be achieved, is their postoperative eating behavior different from norm groups, and which postoperative improvements in eating behavior are attributable to weight loss? We studied eating behavior preoperatively, and on three postoperative moments: 6 months, 1 and 2 years after VBG.

\section{Procedures}

Two types of surgical procedures are used to control morbid obesity: purely restrictive operations and procedures which combine restriction of food intake with malabsorption. Whereas in the USA gastric bypass is the gold standard, in Europe laparoscopic gastric banding and VBG are the most performed techniques. ${ }^{12}$ The restrictive operative technique used in our hospital is hand-assisted laparoscopic VBG (HALS-VBG). ${ }^{13}$ Unlike the original VBG, we completely divide between the vertical staple-lines. ${ }^{14}$ VBG is a relatively simple, safe, and cost-effective intervention with fewer side-effects than other procedures. ${ }^{15}$ Long-term results of VBG have been reported: in general, VBG results in $50 \%$ to $80 \%$ excess weight loss (EWL) ${ }^{16}$ However, also poor long-term results, including weight regain, and dietary and gastrointestinal problems, have been reported. ${ }^{17,18}$
As is reported and advised by many, ${ }^{19,20}$ in our hospital, preoperatively as well as postoperatively, all patients are seen by a multidisciplinary obesity team consisting of a surgeon, gastroenterologist, dietician, and psychologist.

\section{Materials}

Existing studies of psychosocial factors in the surgical treatment of morbid obesity have not produced consistent findings, which may in part be due to methodological limitations and a lack of consensus as to how to measure psychological functioning of the morbidly obese. ${ }^{21,22}$ In our study, preoperatively, all patients were intensively interviewed by a psychologist or by an experienced graduate psychology student, and completed a psychological questionnaire. The preoperative semi-structured interview concerned, among others, motivation for weight loss and VBG, expectations of the procedure and weight loss, dieting history, and eating behavior. In addition, patients filled in the Dutch Eating Behavior Questionnaire (DEBQ), ${ }^{23,24}$ a standardized test with normative data, whose psychometric qualities were mostly judged as satisfactory (norms, reliability, content validity). ${ }^{25}$ The DEBQ measures three eating behaviors: 1) restrained eating, conscious restriction of food intake; 2) emotional eating, eating in response to emotions; and 3) external eating, eating in response to external food-related cues. Six months postoperatively, patients were interviewed again and completed the DEBQ again. The postoperative semi-structured interview concerned mainly weight loss and its consequences, changes in eating habits, and improvements in health and psychosocial functioning. At 1 and 2 years after surgery, patients filled in a written version of the interview, as well as the DEBQ in their home situation and sent it back.

\section{Patients}

In the context of standard preoperative evaluation, 115 patients who underwent VBG in our hosptial between January 2001 and April 2004 were psychologically assessed. As to our inclusion criteria, we followed the criteria determined by the National Institutes of Health Consensus $1991,{ }^{26}$ and IFSO. ${ }^{27}$ In addition, we required $10 \%$ preoperative weight 
loss with a minimum of $12 \mathrm{~kg}$. From these 115 patients, 91 (79.1\%) could be included in our study; others did not respond to our repeated requests for follow-up or sending back the questionnaires. For 6 months' and 1 year follow-up, we had data from 88 and 89 patients, respectively. Because we did not have complete data for all patients on all moments, for most analyses the number of cases was lower than the number of included patients.

The studied patient group consisted of $80(87.9 \%)$ female and 11 (12.1\%) male patients and, preoperatively, had a mean age of $38.6 \pm 8.3$ years, a mean BMI of $45.7 \pm 5.1$, and a mean percentage excess weight of $105.7 \% \pm 22.0$. Male patients were older than female patients (43.6 versus 37.9 years of age; $P \leq .05$ ), and their BMI was higher (48.7 vs $45.1 ; P \leq .05$ ).

\section{Statistical Analyses}

Statistical analyses were performed using the SPSS 14.0-packet (SPSS for Windows, Rel. 14.0. 2005. Chicago: SPSS Inc.). To describe patients' preoperative and postoperative characteristics based on interview data, descriptive statistics were used. To study changes over time in weight as well as in eating behavior, mixed between-within subjects analyses of variance for repeated measures were used (ANOVA; with time as within-subjects factor, and gender as between-subjects factor). To compare patients' questionnaire scores to normative data, we used one-sample $t$-tests, whereas for the comparison of male to female patients' scores, independentsamples $t$-tests were used. To identify relations between changes in eating behavior and weight loss, hierarchical multiple regression was used.

\section{Results}

\section{Weight loss}

Because we require a $10 \%$ preoperative weight reduction from our patients, with a minimum of 12 $\mathrm{kg}$, at all follow-up points, 'postoperative' weight loss also included patients' preoperative weight reduction. Preoperatively, our patients lost a mean weight of $15.3 \pm 6.1 \mathrm{~kg}$. As a result, at the time of surgery, their mean weight was $116.6 \pm 18.4 \mathrm{~kg}$. For our other analyses, we used the original weight at presentation, i.e. before preoperative weight loss. Over time, substantial and significant changes in mean BMI, EW and EWL were found (Table 1). In reporting EWL, we followed the guidelines of Deitel and Greenstein, ${ }^{28}$ using Metropolitan Tables.

Over time, from preoperative status to 2 years after VBG, BMI decreased 13 points, while EW decreased $61.5 \%$. Compared to preoperative status, BMI and EW were significantly lower at all three postoperative follow-up time-points $(P \leq .001)$; according to Cohen, ${ }^{29}$ this suggests a very large effect size. Compared to preoperative weight, there was a significant reduction in BMI and EW after 6 months as well as between 6 months and 1 year after surgery; however, further decrease in BMI and EW from 1 to 2 years did not reach statistical significance. Compared to 6 months postoperatively, there was a significant increase in EWL at 1 and 2 years postoperatively $(P \leq .01)$, being a large effect. ${ }^{29}$ Between 6 months and 1 year, there was a significant increase in EWL; however, further increase from 1 to 2 years was not significant.

To define successful weight loss, we adhered to the Bariatric Analysis and Reporting Outcome System (BAROS). ${ }^{11}$ Over time, the rather low per-

Table 1. Postoperative weight loss (mean \pm sd; EW and EWL in percentages)

\begin{tabular}{lcccc}
\hline & preoperative & 6 months & 1 year & 2 years \\
\hline BMI & $45.7 \pm 5.1$ & $34.2^{\star \star} \pm 5.0$ & $32.6^{*} \pm 5.0$ & $32.1 \pm 6.0$ \\
$\%$ EW & $105.7 \pm 22.0$ & $53.7^{* *} \pm 21.8$ & $46.7^{\star} \pm 21.8$ & $44.1 \pm 26.5$ \\
$\%$ EWL & - & $52.0 \pm 17.8$ & $59.0^{*} \pm 21.3$ & $61.5 \pm 27.5$ \\
$n$ & 77 & 77 & 77 & 77 \\
\hline
\end{tabular}

${ }^{* *} P<.001 ;{ }^{*} P<.01$

BMI: body mass index; EW: excess weight; EWL: excess weight loss.

Because of ANOVA and listwise exclusion, $n=77$ on all time-points. 
centage of patients having poor EWL remained about the same, while the percentage of patients having fair and good EWL decreased, and the percentage of patients having excellent EWL increased. Using a somewhat rougher distribution and defining the operation as successful when EWL was $\geq 50 \%$, and as completely unsuccessful when EWL was $<25 \%,{ }^{30}$ after 2 years, $59.8 \%$ of our patients had a successful operation; on the other hand, $9.2 \%$ had a completely unsuccessful operation. According to the WHO classification of overweight,' preoperatively most of our patients were morbidly obese. At 6 months after surgery, most patients were obese. One and 2 years after surgery, the percentage of obese patients decreased, while the percentages of patients being overweight or having a normal weight increased (Table 2)

\section{Interview}

\section{Motivation and Expectations}

Preoperatively, most patients reported health considerations $(94.5 \%)$ and limitations in activity $(62.6 \%)$ as their primary motives for weight reduction. Having experienced poor results with conservative treatment for their obesity was our patients' most important motivation for bariatric surgery. Their mean maximum, non-surgical weight loss was $25.0 \pm 11.0 \mathrm{~kg}$; however, on average they could sustain a substantial weight loss only for $10.37 \pm 16.7$ months. Most patients expected and hoped to eat less in reaction to getting full and feeling satiated much earlier after surgery, resulting in long-term

Table 2. Success in weight loss ( $\mathrm{N}$ in percentages)

\begin{tabular}{|c|c|c|c|c|}
\hline \multicolumn{2}{|c|}{ Preoperative } & \multirow{2}{*}{$\frac{6 \text { mons }}{5.8}$} & \multirow{2}{*}{$\frac{1 \mathrm{yr}}{10.6}$} & \multirow{2}{*}{$\frac{2 \mathrm{yrs}}{6.9}$} \\
\hline Poor $(0-24 \%$ EWL) & - & & & \\
\hline Fair (25-49\% EWL) & - & 41.4 & 43.5 & 33.3 \\
\hline Good (50-74\% EWL) & - & 47.1 & 34.1 & 34.5 \\
\hline \multicolumn{5}{|l|}{ Excellent } \\
\hline$(75-100 \%$ EWL) & - & 5.8 & 11.8 & 25.3 \\
\hline \multicolumn{5}{|l|}{ Morbidly obese } \\
\hline$(B M I \geq 40$ & 91.2 & 12.6 & 9.4 & 13.8 \\
\hline Obese (BMI 30-40) & 8.8 & 70.1 & 56.5 & 43.7 \\
\hline \multicolumn{5}{|l|}{ Overweight } \\
\hline (BMI 25-30) & - & 14.9 & 28.2 & 34.5 \\
\hline Normal (BMI 20-25) & - & 2.3 & 5.9 & 8.1 \\
\hline $\mathrm{N}$ & 91 & 87 & 85 & 87 \\
\hline
\end{tabular}

changes in eating behavior and weight reduction. They expected/hoped to lose a mean weight of 47.7 $\pm 6.5 \mathrm{~kg}$. Patients not only had positive expectations, but also they feared surgical complications $(42.9 \%)$, and expected some disadvantages such as difficulties in changing their eating behavior $(20.9 \%)$, less social eating (19.8\%), and vomiting in case of non-compliance $(13.2 \%)$.

\section{Eating Behavior}

Preoperatively, most patients $(93.4 \%)$ reported their eating habits as the primary cause for their overweight. Compared to preoperative status, after surgery relatively few patients had frequent feelings of hunger and appetite. In stead, postoperatively, most patients had frequent feelings of satiety and experienced their eating behavior to be limited by their restricted stomach. However, some improvements waned over time, and other patients experienced less or no changes and restrictions (Table 3 ).

Preoperatively, most patients reported eating three meals per day; however, other patients ate only two meals - mostly breakfast was skipped - or used four to six meals per day. Six months after surgery, more patients adhered to three meals a day; however, some fewer patients adhered to this advice over time. Preoperatively, only few patients reported to eat small-sized, low-calorie meals. After surgery, most patients reported to eat small-sized, low-calorie meals. However, over time, they began to eat larger and more calorie-dense meals again. As to snacking, almost the same pattern was reported. In addition, the number of snacks first decreased, but increased later on. Furthermore, preoperatively, a minority of patients reported to binge or graze.

Table 3. Subjective changes in hunger, appetite and satiety (number of patients in percentages)

\begin{tabular}{lcccc}
\hline Experiencing & Preoperative & $6 \mathrm{mos}$ & $1 \mathrm{yr}$ & $2 \mathrm{yrs}$ \\
\hline $\begin{array}{l}\text { Frequent feelings } \\
\text { of hunger }\end{array}$ & 40.4 & 17.6 & 10.1 & 12.6 \\
$\begin{array}{l}\text { Frequent feelings } \\
\text { of appetite }\end{array}$ & 60.2 & 18.8 & 18.0 & 31.0 \\
$\begin{array}{l}\text { Frequent feelings } \\
\text { of satiety }\end{array}$ & - & 90.0 & 79.6 & 79.8 \\
$\begin{array}{l}\text { Limitations from the } \\
\text { restrictive stomach }\end{array}$ & - & 55.6 & 69.0 & 68.6 \\
$\mathrm{~N}$ & 87 & 83 & 88 & 85
\end{tabular}


After surgery, first the number of binges decreased a little, but later on, there was an increase in patients who 'binged', although their binges were much smaller. The number of grazers decreased to almost zero; only two patients reported grazing sometimes. Size and calorie-density of meals and snacks were not objectified but were self-reported by our patients. Finally, most patients reported that they found it easy to change their eating behavior; however, over time, more patients found it difficult to sustain their new eating pattern (Table 4).

\section{Questionnaire}

Eating behavior was assessed using the Dutch Eating Behavior Questionnaire. ${ }^{23,24}$ Over time, we found no significant changes in restrained eating. However, we did find significant changes in emotional eating $(P \leq .001)$; this was a large effect size. ${ }^{29}$ Compared to preoperative status, emotional eating was significantly $(P \leq .01)$ lower 6 months and 1 year postoperatively but not 2 years after surgery. We found a significant decrease in emotional eating between preoperative status and 6 months postoperatively; however, not between 6 months and 1 year postoperatively or between 1 and 2 years. Also, we found significant changes in external eating ( $P \leq .001)$, and again, this was a large effect size. ${ }^{29}$ Compared to preoperative status, external eating was significantly $(P \leq .001)$ lower on all follow-up moments. We found a significant decrease in

Table 4. Subjective changes in eating behavior (number of patients in percentages)

\begin{tabular}{lcccc}
\hline Eating & Preoperative & 6 mos & 1 yr & 2 yrs \\
\hline Three meals per day & 69.7 & 89.1 & 76.4 & 74.4 \\
Small-sized meals & 13.3 & 94.1 & 66.3 & 55.2 \\
Low-calorie meals & 4.4 & 60.0 & 28.1 & 17.4 \\
Mean number of snacks & & & & \\
eaten per day (range) & 3.4 & 1.6 & 2.2 & 2.2 \\
& $(1-10)$ & $(0-5)$ & $(0-5)$ & $(0-5)$ \\
Small-sized snacks & 32.1 & 90.8 & 81.2 & 64.7 \\
Low-calorie snacks & 10.7 & 71.1 & 47.1 & 40.5 \\
'Binge-eating' & & & & \\
$\quad$ (number of binges) & 11.4 & 9.5 & 16.1 & 30.6 \\
& $(1-7)$ & $(1-2)$ & $(1-5)$ & $(1-7)$ \\
Grazing & $9.4 \%$ & 0 & $\approx 0$ & $\approx 0$ \\
Easy to change & & & & \\
eating behavior & - & 68.2 & 62.1 & 56.3 \\
$\mathrm{~N}$ & 87 & 83 & 88 & 85
\end{tabular}

external eating between preoperative status and 6 months postoperatively; however, not between 6 months and 1 year postoperatively or between 1 and 2 years (Table 5). In addition, we found a significant interaction effect as to gender and time $(P \leq .05)$ : compared to preoperative status, at 1 and 2 years postoperatively, male patients reported significantly more external eating ( 1 year $P \leq .05 ; 2$ years $P \leq .01$ ). Between 1 and 2 years after surgery, male patients' external eating decreased somewhat further, whereas female patients' external eating started to increase.

In addition, we compared our patients' median scores to scores of a non-obese norm group (Table $6) .{ }^{24}$ As to restrained eating, preoperatively as well as postoperatively, both female and male patients had significantly higher mean scores. Over time, patients' mean scores decreased slightly; at 2 years after surgery, their scores were not as high as they were preoperatively and 6 months after surgery. As to emotional eating, preoperative female patients' mean scores were significantly higher than in the norm group. At 6 months and 1 year postoperatively, there were no significant differences; however, 2 years after surgery, their mean scores were, again, significantly higher. Compared to the norm group, female patients' mean scores varied between the mean and above the mean range. As to male patients, no significant differences were found and their mean scores varied between below and above mean. As to external eating, preoperatively both female as male patients' mean scores were significantly higher than in the norm group. Postoperatively, their mean scores were significantly lower and fell in the below mean or low range (Table 6).

Table 5. Postoperative changes in eating behavior (mean $\pm \mathrm{sd}$ )

\begin{tabular}{|c|c|c|c|c|}
\hline & Preoperative & $6 \mathrm{mos}$ & $1 \mathrm{yr}$ & 2 yrs \\
\hline Restrained & $3.3 \pm .6$ & $3.3 \pm .7$ & $3.1 \pm .8$ & $3.1 \pm .8$ \\
\hline Emotional & $2.4 \pm .8$ & $1.9^{\star} \pm .8$ & $2.0 \pm .8$ & $2.2 \pm .9$ \\
\hline External & $2.9 \pm .6$ & $2.2^{\star} \pm .6$ & $2.3 \pm .6$ & $2.3 \pm .6$ \\
\hline $\mathrm{N}$ & 81 & 81 & 81 & 81 \\
\hline
\end{tabular}


Table 6. Patients' eating behavior versus a non-obese norm group

\begin{tabular}{|c|c|c|c|c|c|c|c|c|}
\hline & \multicolumn{2}{|c|}{ Preoperative } & \multicolumn{2}{|c|}{6 months } & \multicolumn{2}{|c|}{1 year } & \multicolumn{2}{|c|}{2 years } \\
\hline & females & males & females & males & females & males & females & males \\
\hline Restrained & high $^{\star * \star}$ & $\begin{array}{c}\text { very } \\
\text { high }^{\star \star \star}\end{array}$ & high $^{\star * *}$ & 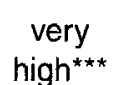 & $\begin{array}{c}\text { above } \\
\text { mean*** }\end{array}$ & $\begin{array}{c}\text { very } \\
\text { high }^{\star \star \star}\end{array}$ & $\begin{array}{c}\text { above } \\
\text { mean*** }\end{array}$ & $h^{\prime} h^{\star \star \star}$ \\
\hline Emotional & $\begin{array}{c}\text { above } \\
\text { mean }^{\star \star \star}\end{array}$ & $\begin{array}{l}\text { above } \\
\text { mean }\end{array}$ & mean & $\begin{array}{l}\text { below } \\
\text { mean }\end{array}$ & mean & $\begin{array}{l}\text { below } \\
\text { mean }\end{array}$ & $\begin{array}{l}\text { below } \\
\text { mean }\end{array}$ & mean \\
\hline External & mean $^{*}$ & high* & $\begin{array}{l}\text { below } \\
\text { mean }{ }^{\star \star *}\end{array}$ & $\begin{array}{l}\text { below } \\
\text { mean }\end{array}$ & $\begin{array}{l}\text { below } \\
\text { mean }\end{array}$ & $\begin{array}{l}\text { below } \\
\text { mean* }\end{array}$ & $\begin{array}{l}\text { below } \\
\text { mean }^{\star \star \star}\end{array}$ & low* \\
\hline $\mathrm{N}$ & 79 & 11 & 77 & 11 & 76 & 11 & 77 & 11 \\
\hline
\end{tabular}

${ }^{\star \star \star *} P<.001 ;{ }^{\star \star} P<.01,{ }^{\star} P<.05$

Relation between Weight Loss and Change in Eating Behavior

At 6 months and 1 year after surgery, a model which included changes in restrained eating, emotional eating and external eating, while controlling for preoperative scores on these variables, significantly $(P \leq .05)$ explained additional variance in EWL $(12.7 \% 6$ months after surgery, $14.5 \% 1$ year postoperatively). Changes in restrained eating made the only statistically significant $(P \leq .05)$ unique contribution ( 6 months after surgery, beta=.35; 1 year postoperatively, beta $=.47)$ and uniquely explained $6.6 \%$ (6 months after surgery) and $11.0 \%$ (1 year postoperatively) of variance in EWL. As to changes in eating behavior, it appeared that changes in restrained eating explained excess weight loss most, at least 6 months and 1 year after surgery.

\section{Male versus Female Patients}

Female patients reported significantly more emotional eating than male patients. However, as to changes in emotional eating, no significant differences were found. Furthermore, we did only find significant interaction effects between time and gender, and in gender differences compared to the norm group. In conclusion, only few significant differences between female and male patients were found.

\section{Heterogeneity in Postoperative Eating Behavior}

In one of our earlier studies, we found that, preoperatively, our patients were a heterogenuous group consisting of three subgroups, ranging from rela- tively good to relatively poor psychosocial functioning on a variety of domains, including eating behavior. ${ }^{31}$ However, few studies have investigated postoperative heterogeneity. In the present study, in addition to a great variation in excess weight loss, we also found a substantial variation in changed eating behavior. We found three groups of patients: one group who reported improvements in their eating behavior, another group who reported a decline, and a small group who reported no change (Table 7). In addition, within these subgroups, there were great variations in changes over time.

\section{Discussion}

In conclusion, over time, we found significant weight loss, especially in the first postoperative year. Patients reported substantial changes in feelings of hunger, appetite, and satiety, and their eating behavior changed significantly; however, most improvements waned over time. Although there were only few gender differences, there was a wide variability in changes within our patient group. Furthermore, although we did not find significant changes in restrained eating over time, weight loss was, partially, correlated to and predicted by changes in restrained eating.

We found similar excess weight loss $(61.5 \%)$ to that reported in other studies, mostly at 2 years weight loss ranging between $40 \%$ and $60 \% .32,33$ However, our patients' weight loss stayed behind the weight losses reported in other studies; $;^{34.35}$ in some of them, obtained due to strict dietary man- 
Table 7. Heterogeneity in changes in eating behavior (number of patients in percentages)

\begin{tabular}{|c|c|c|c|c|c|c|c|c|c|}
\hline & \multicolumn{3}{|c|}{6 months } & \multicolumn{3}{|c|}{1 year } & \multicolumn{3}{|c|}{2 years } \\
\hline & less & more & same & less & more & same & less & more & same \\
\hline Restrained & 51.5 & 38.6 & 10.2 & 59.5 & 34.5 & 6.0 & 50.0 & 45.2 & 4.8 \\
\hline Emotional & 69.3 & 27.3 & 3.4 & 42.9 & 46.4 & 10.7 & 31.0 & 60.7 & 8.3 \\
\hline External & 86.4 & 12.5 & 1.2 & 41.7 & 47.6 & 10.7 & 41.7 & 36.9 & 21.4 \\
\hline $\mathrm{N}$ & 88 & & & 86 & & & 87 & & \\
\hline
\end{tabular}

On all postoperative moments, patient's scores were compared to preoperative status.

agement. ${ }^{34}$ Using a cut-off score of $50 \%$ EWL in defining a successful operation, we had fewer patients having a successful operation $(60 \%)$ than reported in some other studies, reporting success in almost $70 \%$ of their patients. ${ }^{30}$

In contrast to some other studies, ${ }^{36,37}$ we did not find substantial or significant weight regain between 1 and 2 year follow-up. Because a major reduction in comorbidity can be obtained when only part of excess weight is lost, the importance of the exact amount of excess weight loss may not be all that important.

As in other studies, ${ }^{34,38,39}$ after surgery, most of our patients reported eating small amounts of food, decreased energy intake, a decrease in hunger, more early satiety, and more control over their food intake; this may reflect a renewed sense of fullness and a reduction in their preoccupation with food. However, over time, patients reported to eat greater amounts, more snacks and more calorie-dense food. According to some studies, initially after surgery, patients do not have much interest in food, and are focused on eating the 'right' things. Later, however, when they experience a plateau or less rapid weight loss, they lose some of this focus and begin to eat more. ${ }^{40}$

Our findings are in accordance with earlier studies suggesting that weight loss is correlated with improvements in eating behavior. ${ }^{23,38}$ In contrast to some other studies, ${ }^{41,42}$ we found a non-significant decrease in restrained eating, instead of an increase; perhaps less restrained eating results in fewer periods of overeating. This suggestion is consistent with the restraint-theory, which attributes overeating to dieting: attempts to restrict food intake initiate physiological defenses, such as lowering the metabolic rate and persistent hunger, which threaten dieting efforts. ${ }^{24}$ Like others, we did find a decrease in emotional and external eating, ${ }^{4-43}$ and that improvements in eating behaviors waned over time. ${ }^{41,43}$
Also, our findings are partly in line with another study comparing patients' eating behavior to normative scores; however, as to restrained eating, this study found no significant differences. ${ }^{42}$

Our results also support earlier findings concerning postoperative heterogeneity, ${ }^{44}$ in weight loss as well as in eating behavior, and underscore the suggestion that VBG, like other methods of bariatric surgery, is not as effective for each patient.

Although our study has some assets, such as using a standardized, reliable eating behavior questionnaire, some weaker points should be indicated. Like some other studies, we were not able to retain all patients of our preoperative sample; however, our response rate is far above the minimum $(61 \%)$ required by the Standards Committee, ${ }^{45}$ and International Bariatric Surgery Registry. ${ }^{46}$ An optimistic interpretation of this rate of attrition is that many patients are doing well and perceive no reason to return for follow-up visits, suggesting that patients who are lost to follow-up do not necessarily represent failures. ${ }^{47}$ On the other hand, patients may experience difficulties and feelings of shame, guilt, and embarrassment that prevent them from returning. ${ }^{48}$ In addition, we do not have complete data for all patients at all time-points.

Because our group of male patients is rather small, the selection criteria that we use, the preoperative weight loss that we require, and the surgical technique that we use, the generalizability of our results may be limited. Another weak point might be our rather short follow-up period. Because weight regain may occur 2 or 3 years after surgery, ${ }^{49}$ studies using a short followup period may seem irrelevant. However, from the viewpoint of early psychological interventions, and investigating short-term consequences and its correlations, the study may be highly relevant. 
Because obese patients who present for surgical treatment differ from patients not seeking help, ${ }^{50}$ and it is non-ethical to randomly assign patients to surgery or to have patients waiting for a longer period than necessary, ${ }^{8}$ we did not use a control group.

In conclusion, our study demonstrates that, at least within 2 years, VBG not only leads to considerable weight loss, but also to significant improvements in eating behavior. However, improvements waned over time, and not all patients profit in the same way. Perhaps surgery alone is not sufficient to sustain success and additional behavioral treatment may be necessary.

This study was supported by the Scientific Research Fund of the Catharina Hospital, Eindhoven, the Netherlands.

\section{References}

1. World Health Organization. Obesity: preventing and managing the global epidemic. WHO obesity technical report series 2000 , no. 894 . Geneva, Switzerland: World Health Organization, 2000.

2. Wolf AM, Falcone AR, Kortner B et al. BAROS: An effective system to evaluate the results of patients after bariatric Surgery. Obes Surg 2000; 10: 445-50.

3. World Health Organization (2002). The World Health Report 2002. Reducing risks, promoting healthy life. Geneva: WHO.

4. Shai I, Henkin Y, Weitzman S et al. Determinants of long-term satisfaction after vertical banded gastroplasty. Obes Surg 2003; 13: 269-74.

5. Larsen JK, Geenen R, Van Ramshorst B et al. Psychosocial functioning before and after laparoscopic adjustable gastric banding: a cross-sectional study. Obes Surg 2003; 13: 629-36.

6. Mamplekou E, Komesidou V, Bissias $\mathrm{CH}$ et al. Psychological condition and quality of life in patients with morbid obesity before and after surgical weight loss. Obes Surg 2005; 15: 1177-84.

7. Schirmer B, Watts SH. Laparoscopic bariatric surgery. Surg Endosc 2004; 18: 1875-8.

8. Bocchieri LE, Meana M, Fisher BL. A review of psychosocial outcomes of surgery for morbid obesity. J Psychosom Res 2002; 52: 155-65.

9. Kalarchian MA, Marcus MD, Wilson T et al. Binge eating among gastric bypass patients at long-term follow-up. Obes Surg 2002; 12: 270-5.

10. Gentry K, Halverson JD, Heisler S. Psychological assessment of morbidly obese patients undergoing gastric bypass: a comparison of pre-operative and postoperative adjustment. Surgery 1984; 95: 215-20.

11. Oria HE, Moorehead MK. Bariatric analysis and reporting outcome system (BAROS). Obes Surg 1998; 8: 487-99.

12. Hell E, Miller KA, Moorehead MK et al. Evaluation of health status and quality of life after bariatric surgery: comparison of standard Roux-en- $Y$ gastric bypass, vertical banded gastroplasty and laparoscopic adjustable silicone gastric banding. Obes Surg 2000; 10: 214-9.

13. Van de Walle P, Van Outryve L. Hand-assisted laparoscopic vertical banded gastroplasty: Technique and analysis of the first 140 cases. Obes Surg 2002; 12 : 628-33.

14. Mason EE, Maher JW, Scott DM et al. Ten years of vertical banded gastroplasty for severe obesity. Prob Gen Surg 1992; 9: 280-9.

15. Van Gemert WG, Adang EMM, Kop $M$ et al. A prospective cost-effectiveness analysis of vertical banded gastroplasty for the treatment of morbid obesity. Obes Surg 1999; 9: 484-91.

16. Brolin RE. Critical analysis of results: Weight loss and quality of data. Am J Clin Nutr 1992; 55: 577S81.

17. Kalfarentzos F, Kechagias I, Soulikia K et al. Weight loss following vertical banded gastroplasty: intermediate results of a prospective study. Obes Surg 2001; 11: 265-70.

18. Arribas del Amo D, Martínez Díez M, Guedea ME et al. Vertical banded gastroplasty: is it a durable operation for morbid obesity? Obes Surg 2004; 14: 536-8.

19. Bauchowitz AU, Gonder-Frederick LA, Olbrisch ME et al. Psychosocial evaluation of bariatric surgery candidates: a survey of present practices. Psychosom Med 2005; 67: 825-32.

20. Sauerland S, Angrisani L, Belachew M et al. Obesity surgery. Evidence-based guidelines of the European Association for Endoscopic Surgery (E.A.E.S.). Surg Endosc 2005; 19:200-21.

21. Papageorgiou GM, Papakonstantinou A, Mamplekou E et al. Pre- and postoperative psychological characteristics in morbidly obese patients. Obes Surg 2002; 12: 534-9.

22. van Hout GCM, Leibbrandt AJ, Jakimowicz JJ et al. Bariatric surgery and bariatric psychology: General overview and the Dutch approach. Obes Surg 2003; 13, 926-31.

23. Van Strien T. Dutch Eating Behavior Questionnaire. Suffolk: Thames Valley Test Company Limited 2002. 24. Van Strien T, Frijters JER, Bergers GPA et al. Handleiding Nederlandse Vragenlijst voor Eetgedrag [Manual Dutch Eating Behavior Questionnaire]. 
Lisse: Swets \& Zeitlinger 1986.

25.Evers A, Vliet-Mulder JC van, Groot CJ. Documentatie van tests en testresearch in Nederland [Documentation of tests and testresearch in the Netherlands]. Amsterdam: NIP 2000. NIP.

26. National Institutes of Health Consensus Development Conference Draft Statement. Gastrointestinal surgery for severe obesity. Obes Surg 1991; 1: 257-66.

27. IFSO Statement on patient selection for surgery. Obes Surg 1997; 7: 41 .

28. Deitel M, Greenstein RB. Recommendations for reporting weight loss. Obes Surg 2003; 13: 159-60.

29. Cohen J. Statistical Power Analysis for the Behavioral Sciences, 2nd Edn. Hillsdale, NJ: Lawrence Erlbaum Associates, 1988.

30. Kalfarentzos F, Skroubis G, Kehagias I et al. A prospective comparison of vertical banded gastroplasty and roux-en-y gastric bypass in a non-superobese population. Obes Surg 2006; 16: 151-8.

31. Van Hout GCM, van Oudheusden I, Krasuska AT et al. Psychological profile of candidates for vertical banded gastroplasty. Obes Surg 2006; 16: 67-74.

32. Fox SR, Oh KH, Fox K. Vertical banded gastroplasty and distal gastric bypass a primary procedures - a comparison. Obes Surg 1996; 6: 421-5.

33. Kalfarentzos F, Dimakopoulos A, Kehagias MD et al. Vertical banded gastroplasty versus standard or distal Roux-en-Y gastric bypass based on specific selection criteria in the morbidly obese: preliminary results. Obes Surg 1999; 9: 433-42.

34. Avsar FM, Ozel H, Topaloglu S et al. Improvement of vertical banded gastroplasty by strict dietary management. Obes Surg 2004, 14: 265-70.

35. Van Dielen FMH, Soeters PB, De Brauw LM et al. Laparoscopic adjustable gastric banding versus open vertical banded gastroplasty: a prospective randomized trial. Obes Surg 2005; 15: 1292-8.

36. Wang W, Yu PJ, Lee YC et al. Laparoscopic vertical banded gastroplasty: 5-year results. Obes Surg 2005; 15: 1299-303.

37. Baisiger BM, Poggio $\mathrm{J}$, Mai $\mathrm{J}$ et al. Ten and more years after vertical banded gastroplasty as primary operation for morbid obesity. J Gastrointest Surg 2000; 4: 598-605.

38. Guisado JA, Vaz FJ, Alarcón J et all. Psycho- pathological status and interpersonal functioning following weight loss in morbidly obese patients undergoing bariatric surgery. Obes Surg 2002; 12: 835-40.

39. Kriwanek S, Blauensteiner W, Lebisch $E$ et al Dietary changes after vertical banded gastroplasty. Obes Surg 2000; 10: 37-40.

40. Saunders R. "Grazing": a high-risk behavior. Obes Surg 2004; 14: 98-102.

41.Larsen J K, Van Ramshorst B, Geenen R et al. Binge eating and its relationship to outcome after laparoscopic adjustable gastric banding. Obes Surg 2004; 14: $1111-7$.

42. Hörchner R, Tuinebrejjer W, Kelder H. Eating patterns in morbidly obese patients before and after a gastric restrictive operation. Obes Surg 2002; 12: 108-12.

43. Hsu LK, Sullivan SP, Benotti PN. Eating disturbances and outcome of gastric bypass surgery: a pilot study. Int J Eat Disord 1997; 21: 385-90.

44. Pessina A, Andreoli M, Vassalo C. Adaptability and compliance of the obese patient to restrictive gastric surgery in the short term. Obes Surg 2001; 11: 45963.

45. Standards Committee, American Society for Bariatric Surgery. Guidelines for reporting results in bariatric surgery. Obes Surg 1997; 7: 521-2.

46. Renquist KE, Cullen JJ, Barnes D et al. The effect of follow up on reporting success for obesity surgery. Obes Surg 1995; 5: 285-92.

47. Bocchieri LE, Meana M, Fisher BL. A review of psychosocial outcomes of surgery for morbid obesity. $\mathrm{J}$ Psychosom Res 2002; 52: 155-65.

48. Sarwer DB, Wadden TA, Fabricatore AN. Psychosocial and behavioral aspects of bariatric surgery. Obes Res 2005; 13: 639-48.

49. Pérez N, Baltasar A, Serra C et al. Comparative analysis of vertical banded gastroplasty and duodenal switch at five years follow-up. Obes Surg 2005; 15: 1061-5.

50. Fitzgibbon ML, Stolley MR, Kirschenbaum DS. Obese people who seek treatment have different characteristics than those who do no seek treatment. Health Psychol 1993; 12: 342-5.

(Received November 17, 2006; accepted January 12, 2007) 